\title{
"A água é pra vida e não pra morte": crítica sociológica do modelo de desenvolvimento econômico na Amazônia Setentrional
}

\author{
Vinícius Barriga Santos \\ Recebido em maio de 2019 \\ Aceito em outubro de 2019
}

\begin{abstract}
RESUMO
O presente artigo objetiva analisar e avaliar, a partir de uma perspectiva sociológica, os impactos socioambientais e econômicos facejados pela população de Ferreira Gomes, município do Estado do Amapá no norte do Brasil, decorrentes da construção das usinas hidrelétricas F. Gomes, C. Nunes e C. Caldeirão ao longo do Rio Araguari localizado no supracitado município, atentando o foco analítico para a dimensão da territorialidade. Para tanto, o itinerário percorrido perpassará por uma caracterização dos pressupostos históricos que fundamentam o modelo de desenvolvimento vigente na Amazônia, para então demonstrarmos suas consequências empíricas a partir de dados colhidos, via observação participante e análise documental, em Ferreira Gomes. Compreende-se que o escopo teórico aqui adotado insere-se nos esforços em consolidar uma "Sociologia da Amazônia", cujo objetivo consiste em dar fundamentações críticas e dimensionar a esfera político-ideológica dos fatores antropogênicos nos problemas ambientais. Em suma, o artigo em tela consiste em uma análise crítica do modelo desenvolvimentista imposto à região amazônica, problematizando o paradoxo onde o desmatamento, a perda da biodiversidade, os danos às comunidades, os incomensuráveis danos ambientais etc. seriam legitimados e justificados em nome de um suposto "desenvolvimento".
\end{abstract}

Palavras-chave: Sociologia da Amazônia; Conflitos Socioambientais; Desenvolvimento; Amazônia.

\section{ABSTRACT}

This article aims to analyze and evaluate, from a sociological perspective, the socio-environmental and economic impacts faced by the population of Ferreira Gomes, municipality of Amapá state in northern Brazil, resulting from the construction of the hydroelectric power plants F. Gomes, C. Nunes and C. Cauldron along the river "Araguari" located in the aforementioned municipality, paying attention to the analytical focus on the dimension of territoriality. To this end, the itinerary covered will permeate a characterization of the historical assumptions that underlie the current development model in the Amazon, and then demonstrate its empirical consequences from data collected through participant observation and document analysis in Ferreira Gomes. It is understood that the theoretical scope adopted here is part of the efforts to consolidate a "Sociology of the Amazon", whose objective is to provide critical foundations and to dimension the political-ideological sphere of anthropogenic factors in environmental problems. In short, the article consists of a critical analysis of the developmental model imposed on the Amazon region, problematizing the paradox where deforestation, loss of biodiversity, damage to communities, immeasurable environmental damage, etc. would be legitimized and justified in the name of a supposed "development".

${ }^{1}$ Integrante do Laboratório de Antropologia Simbólica e Etnografia dos Povos Amazônicos LABANT. Voluntário do Programa de Educação Tutorial (PET) Conexão de Saberes de Ciências Sociais. E-mail:vsbarriga@gmail.com 
Keywords: Sociology of Amazon; Socio-environmental conflicts; Development; Amazon.

$\mathrm{T}$ alvez não haja na sociologia brasileira temática tão complexa quanto a Amazônia, seu caráter polissêmico e polimórfico dificulta um dos imperativos do oficio sociológico, qual seja, a sua construção enquanto objeto de estudo: reúne-se sob a égide de um mesmo termo, Amazônia, uma rede inextrincável de fatos, imagens e ideias. Ora designa uma imensa bacia hidrográfica coberta por uma extensa e rica floresta tropical que abrange uma biodiversidade incomensurável, ora remete a multiculturas e etnias ou a uma região cercada de mistérios, intocada e a ser "desbravada", a "terra sem gente", conforme discurso militar no período ditatorial, outrossim, ao próprio mito grego das amazonas que Frei Gaspar de Carvajal constatou a veracidade, conforme as suas cartas, ao ter supostamente avistado mulheres guerreiras em suas navegações na foz do Rio Negro. Para além de permanecermos na inércia, estáticos e impotentes pela perplexidade que o tema suscita a partir de uma apreensão fenomênica, nosso recorte analítico, assim como a especificidade do presente estudo, perpassará pela constatação de que a Amazônia brasileira, tendo a maior disponibilidade hídrica superficial, atmosférica e subterrânea do Brasil, a partir da década de 1980, tornou-se alvo de grandes investimentos industriais, máxime, no setor de produção de energia, que almeja construir diversas hidrelétricas nas bacias hidrográficas amazônicas. Neste diapasão, as demandas de expansão e de consolidação do sistema energético brasileiro e o desenvolvimento regional e, sobretudo, o nacional, são os impulsores e justificativas para a efetivação destes grandes projetos.

Entretanto, tais empreendimentos industrial-econômicos, vistos da perspectiva de um modelo de desenvolvimento que historicamente mostrou-se pernicioso para a região, engendra uma série de danos totais (econômico, social, ambiental) às comunidades amazônicas. Destarte, o locus empírico do presente artigo situa-se em Ferreira Gomes, um município do Estado do Amapá no norte do Brasil, especificamente na região setentrional amazônica, sua população, constituída prioritariamente de pescadores e pequenos comerciantes, era estimada no último censo demográfico em 2010 de 7.087 habitantes (IBGE, 2010) e a sua área geográfica é 
de $5047 \mathrm{~km}^{2}$. Situado a $137 \mathrm{~km}$ de distância da capital Macapá, este município, desde 1980, tem sido alvo de grandes projetos desenvolvimentistas, onde se deu a construção das usinas hidrelétricas Ferreira Gomes, Coaracy Nunes e Cachoeira Caldeirão que são constituintes do Programa de Aceleração do Crescimento (PAC-2) do governo federal, cujo objetivo é a expansão da matriz energética do Brasil. As supracitadas usinas hidrelétricas foram construídas ao longo do Rio Araguari, um corpo hídrico de fundamental importância para a biodiversidade, cultura e economia local que estrutura-se principalmente pela pesca.

Neste sentido, o presente artigo tem como objetivo analisar e avaliar, a partir de uma perspectiva sociológica, os impactos sociais e econômicos oriundos dos danos ambientais (morte em massa de peixes, inundações pela elevação do nível do rio) facejados pela população de Ferreira Gomes e os conflitos sociais decorrentes, atentando para a dimensão da territorialidade da comunidade (RAFFESTIN, 1993; HAESBAERT, 1994). Não obstante, contamos com um olhar elucidativo sobre a ação dos atores-chave (movimentos sociais, associações de pescadores, prefeitura e Estado) no que tange as consequências adjacentes à construção e o funcionamento efetivo das usinas hidrelétricas Ferreira Gomes, Coaracy Nunes e Cachoeira Caldeirão.

A pesquisa de campo ocorreu no contexto do projeto de pesquisa intitulado "Desenvolvimentismo na Amazônia” do Programa de Educação Tutorial (PET) Conexões de Saberes de Ciências Sociais, da Universidade Federal do Amapá (UNIFAP), sob a tutoria do Professor Dr. Manoel Pinto. Neste sentido, a metodologia adotada consiste em uma imbricação de duas técnicas da pesquisa social, a observação participante e a análise documental (GOMES, 1994). Consultou-se o arquivo da Secretaria do Estado de Meio Ambiente (SEMA) do município de Ferreira Gomes visando à coleta de dados acerca das usinas hidrelétricas, bem como os conteúdos jornalísticos produzidos pelos portais de notícias regionais e locais. A observação participante se realizou no município de Ferreira Gomes a partir de viagens periódicas a campo que se deram entre junho de 2018 a fevereiro de 2019, neste contexto o locus da pesquisa centrou-se especificamente nas áreas mais afetadas, como o bairro de pescadores denominado de "matadouro". A imersão neste campo de pesquisa 
permeou-se de múltiplos relatos de moradores acerca do descaso das instituições públicas para com suas vidas, direitos e bens em um contexto de intensos conflitos entre a administração das usinas hidrelétricas e a população; neste ínterim, a convivência com os interlocutores tornou-se central para a apreensão e elucidação dos sentidos atribuídos a todo o processo de instauração e efetivação das hidrelétricas e, principalmente, a recepção e percepção dos moradores aos intensos impactos territoriais, econômicos e psicossociais subjacentes a estes grandes projetos.

Contamos ainda com entrevistas semiestruturadas com moradores e pescadores da região, incluindo o representante regional do Movimento dos Atingidos por Barragens (MAB), Morone Guimarães, cuja atuação é intensa e ativa na luta pelas compensações e indenizações à população atingida através dos Termos de Ajustamento de Conduta Ambiental (TAC) criados e assinados pela articulação entre Ministério Público Federal, Empresas responsáveis pela administração das hidrelétricas e a população local.

Compreende-se que o escopo teórico aqui adotado insere-se nos esforços em consolidar uma sociologia da Amazônia, no intuito de dar fundamentações críticas e dimensionar a esfera político-ideológica dos fatores antropogênicos implicados nos impactos ambientais. Destarte, não negligenciando o necessário dialogo interdisciplinar que a complexidade da temática suscita, uma apreensão sociológica do problema em questão adquire potencial heurístico na possibilidade de desvelar alternativas sustentáveis de desenvolvimento econômico, assim como possui capacidade de fornecer diagnósticos que se configuram enquanto meios de intervenção e gestão dos supramencionados conflitos ambientais e sociais a partir de políticas públicas sociologicamente orientadas. Sendo assim, o itinerário aqui percorrido perpassará por uma caracterização dos pressupostos históricos que fundamentam e legitimam o modelo de desenvolvimento vigente e os subjacentes grandes projetos econômicos na Amazônia, para então demonstrar, analisar e avaliar suas consequências a partir dos dados empíricos atinentes a Ferreira Gomes no que tange aos processos de efetivação das construções dos projetos e os impactos subsequentes. 
Não obstante, esforçar-se-á por ilustrar, a partir do caso particular de Ferreira Gomes, as nuanças e perversidades do modelo de desenvolvimento imposto à Amazônia em geral, assim como suas raízes que remetem ao modus operandi do sistema colonial, reproduzindo as próprias mazelas do passado colonialista transmutado e legitimado sob o imperativo de um "progresso" e "modernização" no tempo presente. Diz-se que o Brasil é fruto de diversos paradoxos; não há duvidas de que o seja, destarte, a incumbência de uma sociologia feita na e da Amazônia consiste no esforço em elucidar analiticamente, a partir de uma epistemologia apropriada a complexidade do objeto, estes próprios paradoxos. À vista disto, encontrar-se-á, a partir de um exame sociológico do caso de Ferreira Gomes, as seguintes dicotomias que dimensionam problemáticas cruciais e gerais da região amazônica: expansão da matriz energética versus preservação do sistema ecológico; desenvolvimento econômico-industrial versus direitos dos povos tradicionais; lógica capitalista do lucro versus lógica do bem-viver das comunidades locais.

\section{Pressupostos históricos do modelo de desenvolvimento na Amazônia.}

Por ser a Amazônia uma região situada numa posição periférica no interior de países periféricos do sistema-mundo capitalista moderno, lhe escapa até mesmo o poder de falar sobre si mesma, desta forma, prevalecem visões sobre a Amazônia, e não visões da Amazônia, isto é, da população amazônica e seus interesses (GONÇALVES, 2018, p.25). Neste sentido, é fundamental analisar os pressupostos do modelo desenvolvimentista imposto à Amazônia a partir de uma introspecção histórica visando jogar luz ao desenvolvimento regional amazônico em sua configuração atual. A imersão na historicidade amazônica objetivará chamar a atenção para os paradoxos que impulsionaram o processo de anexação da região ao Brasil no período imperial engendrando, conforme demonstraremos, a subalternização da Amazônia em relação ao centro de constituição político-econômico do Brasil, isto é, o centro-sul.

No princípio, segundo Márcio Souza (2002, p.31), a Amazônia não pertencia ao Brasil, descoberta em 1498 e efetivamente ocupada pelos portugueses apenas em 1630, deste 
modo, a Coroa Portuguesa possuía duas colônias na América do Sul, o Grão-Pará (região amazônica) e o Brasil, que se desenvolveram dissociadas entre si até a anexação em 1823, logo, originando, durante o período de pré-anexação, uma diferenciação entre ambas nas dimensões político-econômica e cultural (SOUZA, 2002, p.32). Anterior à anexação, a colônia Grão-Pará (Amazônia) caracterizava-se economicamente pela produção manufaturada com menor dependência de mão-de-obra escrava, as transformações do látex adquiririam centralidade com a economia da borracha ainda em fase de florescimento; havia também uma indústria naval e uma agricultura capitalista de pequenos proprietários, além da modernidade econômica sucedia-se uma cultura urbana em pleno desenvolvimento em Belém, a capital administrativa (SOUZA, 2002, p.32). Em divergência, a colônia Brasil fundava-se na excessiva dependência em relação à agricultura de grandes latifúndios e na agroindústria, dependendo compulsoriamente de mão-de-obra escrava. Explicitando a distinção entre as duas colônias, Souza dirá:

Em meados do século XVIII, tanto o Grão-Pará quanto o Brasil conseguem
criar uma forte classe de comerciantes, bastante ligados à importação e
exportação, senhores de grandes fortunas e bastantes autônomos em relação à
Metrópole. Mas, enquanto os comerciantes do Rio de Janeiro deliberadamente
optaram pela agricultura de trabalho intensivo, como o café, baseando-se no
regime da escravidão, os empresários do Grão-Pará intensificaram seus
investimentos na indústria naval e nas primeiras fábricas de beneficiamento
de produtos extrativos, especialmente o tabaco e a castanha-do-pará (SOUZA,
2002, p.32).

O desenvolvimento distinto e dissociado entre as duas colônias supracitadas e a decorrente diferenciação possui papel capital para a neutralização e o não reconhecimento das modernas experiências econômicas locais do Grão-Pará no processo de anexação da região ao Brasil. Desdobrando-se em repressões e convulsões sociais, a anexação, a partir de 1823, destruiu todos os focos de modernidade amazônicos (SOUZA, 2002, p.33). A argumentação fundamental de Márcio Souza perpassa pela incapacidade do governo central em reconhecer e aceitar o desenvolvimento local prévio do Grão-Pará, logo, a anexação deu-se em detrimento da história e vozes locais, neste aspecto, a desconsideração de que "a modernidade já foi 
feita na região", conforme aponta Souza (2002, p.4), redunda em uma conclusão paradoxal: a modernidade experienciada pela Amazônia foi neutralizada pelo processo de integração, cujo adágio consistia na própria incumbência de "levar a modernidade" para região.

Destarte, em última análise, no processo de anexação a Amazônia foi reinventada, reformulada e ressignificada pelo Brasil, que projetou para ela certas imagens e representações sociais que configuram um imaginário coletivo que exerceu/exerce e ainda exercerá papel fundante em relação à formulação e legitimação de políticas sobre e para a região: a imagem da Amazônia como natureza prístina; a Amazônia como vazio demográfico; Amazônia como reserva e fonte inesgotável de recursos; Amazônia como região do futuro. Essas imagens rigorosamente consistem em atualizações e expressões hodiernas do imaginário colonial, datando a formação histórica da região a partir da chegada dos "descobridores", senão invasores, desprezando a ocupação milenar da região por culturas originárias, estas imagens coloniais naturalizam a violência simbólica, silenciam e invisibilizam os povos, etnias, nacionalidades, comunidades negras, quilombolas e camponesas (GONÇALVES, 2018, p.26). Em nível de dilucidação: a perniciosidade que subjaz à imagem do "vazio demográfico", na medida em que estabelece a vacuidade humana na região, reduz a Amazônia a uma natureza prístina e inesgotável, logo, uma fonte incomensurável de recursos naturais que podem e devem ser exploradas pelo aparato estatal em associação com empresas capitalistas para levar a região ao "progresso", ao “desenvolvimento".

Este discurso dominante/colonial, compreendido como instrumento estruturado e estruturante de dominação, objetiva estabelecer a apreensão da ordem estabelecida, do status quo, como algo natural, um dado intrínseco à realidade por intermédio da imposição mascarada de categorias e sistemas de classificações (BOURDIEU, 2006, p.14), cujo epítome se dá na categorização da Amazônia como um vazio demográfico, "terra sem gente”. Não obstante, o caráter ideológico deste discurso será diluído pelo olhar sociológico, olhar este que permite a tomada de consciência do arbitrário (BOURDIEU, 2006, p.15), ao desvelarmos os determinados dispositivos 
históricos que atuaram enquanto mecanismos de legitimação, possibilitando estas próprias concepções e práticas que destruíram os focos da modernização amazônica, qual seja: o secular dispositivo discursivo acerca do "Progresso" e do “Desenvolvimento".

A origem social deste discurso remonta, segundo Violeta Loureiro (2012, p.520), ao iluminismo, o apogeu da racionalidade e berço do capital, no qual a noção de "Progresso" exercia caro senão fundante papel para o pensamento da época, onde a expressão mais acabada de tal noção deu-se na dimensão da economia do capitalismo industrial, destarte, o agravante de tal constatação engendrar-se-á pelo fato de que o progresso material pressupondo o padrão de consumo crescente dos países colonialimperialistas ocidentais foi erigido, ele próprio, enquanto o modelo econômico exemplar, configurando-se como o ideal a ser atingido pelas outras sociedades e, por consequência, a identificação entre "progresso material" e "desenvolvimento" (LOUREIRO, 2012, p.527). Semelhante discurso arquiteta uma ideologia, na qual não há senão um único meio para alcançar o estado de bem-estar social e o desenvolvimento pleno, a saber, através da adoção, por parte dos países colonizados e subdesenvolvidos, do padrão de desenvolvimento dos países hegemônicos ocidentais (LOUREIRO, 2012, p.528)

As implicações totais (políticas, sociais, econômicas, ambientais) de tal discurso são fatidicamente conhecidas pela América Latina e em especial a Amazônia, sobretudo, pela imersão da região em um processo de mimetismo colonial, conforme Homi Bhabha (2001, p.14), no qual as imagens, projetos e políticas são engendradas a partir das categorias colonial-imperialistas dos países ocidentais hegemônicos que reproduzem própria a subalternização da Amazônia e seu povo, o que explicita-se nas próprias propostas de desenvolvimento pós-anexação, neste aspecto assevera Loureiro:

[...] as diversas experiências de desenvolvimento propostas para a Amazônia faliram em sua missão de desenvolver a região; são excludentes, comprometem ou destroem a rica multiculturalidade da Amazônia, levam à homogeneização cada vez maior das sociedades, dissolvendo num todo comum as particularidades e especificidades dos grupos sociais; são concentradores de renda, geram poucos empregos, espalham miséria em torno dos grandes empreendimentos onde se implantam e provocam enormes danos ambientais (LOUREIRO, 2012, p.529). 
Constata-se, deste modo, que o modelo econômico de organização da produção prevalecente na região foi formulado sob a égide dos princípios regentes do mercado mundial, no qual a Amazônia detém uma desvantagem a priori pela própria configuração da divisão internacional do trabalho que reduz economia local a mera fonte de commodities, reproduzindo o secular modelo colonial agroexportador (LOUREIRO, 2012, p.530). Segundo Loureiro:

[...] o atual modelo amazônico de desenvolvimento está ancorado em empreendimentos que produzem bens semielaborados e matérias-primas, destinados à exportação. Apesar de gerar poucos empregos, já que as cadeias produtivas não se completam para produzir bens finais; de desalojar populações naturais e tradicionais; de consumir enormes quantidades de energia de exaurir a natureza e colocá-la em permanente perigo, esse modelo de produção, baseado nas duas classes de produtos referidas - semielaborados e matérias-primas -, tem sido apoiado por políticas públicas continuadas, que reproduzem com poucas alterações o secular modelo colonial agroexportador. Pelos males que carrega consigo, trata-se de desenvolvimento degenerativo, posto que quanto mais avança e se aprofunda, maiores danos provoca (LOUREIRO, 2012, p.530).

O caráter degenerativo deste desenvolvimento é engendrado pela sua subserviência a lógica irresistível do capitalismo, deste modo, o modelo desenvolvimentista e os grandes projetos impostos à Amazônia objetivam facilitar a circulação das mercadorias no espaço geográfico e intensificar a produção e a acumulação de capital. Neste sentido, o combate à pobreza e ao subdesenvolvimento, o desenvolvimento regional e a extensão de benefícios econômicos às populações tradicionais muitas vezes não servem senão enquanto recurso retórico para a legitimação social a nível discursivo destes grandes projetos, não obstante, vale enfatizar que o que baliza tais empreendimentos é a lógica do capital: "produzir mais", isto é, gerar lucros, e para tanto é necessário aumentar a produção de energia que torne o lucro reprodutível (GONÇALVES, 2018, p.28).

Neste contexto, grande parte dos megaprojetos de produção de energia corresponde a sempre crescente e irresistível demanda energética, a qual é função direta do processo de urbano-industrialização sob o impulso da acumulação de capital, portanto, segundo Gonçalves (2018, p.65), a Amazônia também tem passado por 
intenso processo de urbanização nas últimas três décadas e, assim, há uma demanda crescente de energia da própria região, entretanto, o maior impulso disto é dado pela integração da região aos mercados globais, isto é, pelas demandas exógenas à região. Dirá o autor:

Até 2012, existiam na Amazônia 171 hidroelétricas em operação ou em
construção, das quais 120 com capacidade de até $30 \mathrm{mw}$, as chamadas PCH
(Pequenas Centrais Hidrelétricas). Estão previstas, até 2020, a construção de
outras 246 hidrelétricas nos planos energéticos nacionais, sendo a maior parte
PCH (179). Ou seja, um aumento espetacular de $144 \%$ do número total de
hidrelétricas, sendo de $149 \%$ de PCH e de $131 \%$ no número de grandes
hidrelétricas (UHE) (GONÇALVES, 2018, p. 71).

Em síntese, conforme demonstraremos a partir dos dados empíricos, refletir criticamente sobre os megaprojetos de desenvolvimento econômicos impostos à Amazônia é reconhecê-los enquanto articuladores de conflitos, de desmatamento e de caos ambiental. As demandas de expansão da matriz energética, para sustentar este modelo insustentável de desenvolvimento econômico, impõem uma intensa pressão sobre a Amazônia e os povos tradicionais que habitam a região desde tempos originários. Neste contexto, nota-se que os poderosos grupos econômicos hegemônicos que protagonizam e financiam este padrão de expansão industrial-econômico, voraz e insaciável nas suas demandas por matéria e energia, estão impondo dificuldades para reconhecer as territorialidades comunitárias, fazer a demarcação das terras ou respeitar os direitos da natureza e mesmo levar à prática o Convênio 169 da OIT ou a Declaração dos Direitos Indígenas da ONU, grandes marcos jurídico-sociais no reconhecimento dos direitos dos povos tradicionais. Neste diapasão dirá Gonçalves:

Segundo a CPT, desde 2006, no Brasil, registra-se que as populações tradicionais são as maiores vítimas do avanço industrial/agrícola, pois é na Amazônia que estão 6o\% das localidades onde ocorreram conflitos. Segundo o CIMI, mais de 56o lideranças indígenas foram assassinadas entre 2005 e 2015 no Brasil. A rodovia Transamazônica, por exemplo, foi construída sob a consigna de que a Amazônia era uma terra sem gente para onde deveriam ir os trabalhadores sem terra do Nordeste, assim como foram estimulados os "colonos" do sul do país a vender suas "colônias" e comprar terras mais baratas em projetos de colonização oficiais ou privados na Amazônia. As políticas oficiais de ocupação de terras na Amazônia se fazem a título de colonização e como contra a reforma agrária. Isso não impediu, entretanto, que cerca de 30\% das terras ocupadas recentemente na Amazônia estejam em mãos de 
pequenos produtores rurais, a maior parte deles vindos de outras regiões e sem conhecimento do complexo metabolismo ecológico amazônico. O mesmo se pode dizer, nesse aspecto, dos grandes proprietários que chegam à região com a mentalidade de querer a terra nua, e não a floresta. A floresta, assim como os seus contrafortes andinos, é vista como obstáculo (GONÇALVES, 2018, p.77).

Portanto, no cerne dos grandes projetos econômicos há uma contradição premente entre a exploração de recursos naturais e a preservação e reconhecimento de direitos fundamentais dos povos que historicamente ocupam a região amazônica. Conforme Gonçalves (2018, p.78), o primado do direito liberal-capitalista que regulamenta as relações sociais e as de poder implica a desterritorialização das territorialidades comunitárias ao considerar o interesse nacional a partir de uma perspectiva colonial que ignora as especificidades ontológicas das múltiplas etnias, povos e nacionalidades que ocupam a Amazônia, almejando integrar e reduzir esta diversidade à unicidade compulsória dos signos nacionais (GONÇALVES, 2018, p.77). Destarte, objetivando a manutenção da identidade cultural e os direitos fundamentais das comunidades amazônicas, mecanismos de proteção dos povos tradicionais foram criados em âmbito internacional, e são aplicados nacionalmente de diferentes formas nos diversos países, como a supracitada Convenção 169 da Organização Internacional do Trabalho (OIT) e a Declaração dos Direitos dos Povos Indígenas aprovada pela Organização das Nações Unidas (ONU), esta última foi ratificada no Brasil pelo Congresso Nacional e incorporada ao Ordenamento Jurídico brasileiro através do Decreto 5.051/2004, que trata, dentre outros assuntos, da preservação da integridade étnica e cultural dos povos comunitários, dos direitos originários sobre as terras que ocupam e sobre os recursos naturais nelas existentes, cujos objetivos perpassam pela garantia da igualdade de direitos entre indígenas e outros cidadãos, máxime no que tange aos direitos humanos (ALMEIDA, 2016, p. 107).

Neste contexto desenvolvimentista de inúmeras transgressões e violações dos direitos dos povos amazônicos, pesquisas que objetivem analisar e avaliar os impactos sociais causados por estes grandes projetos às comunidades tradicionais e a partir deles debater os paradoxos que lhes são subjacentes adquirem importância em demasia, sobretudo, pela possibilidade de fornecer informações especializadas para políticas 
públicas que potencialmente podem mitigar este paradoxo entre exploração de recursos naturais e proteção dos povos supracitados (ALMEIDA, 2016, p.93).

\section{Implicações do modelo de desenvolvimento a partir do caso particular de Ferreira Gomes: os múltiplos impactos}

O município de Ferreira Gomes é condicionado, em múltiplas esferas, pela ação das hidrelétricas Coaracy Nunes, Ferreira Gomes e Cachoeira Caldeirão, estas se instalaram ao longo do baixo e médio Rio Araguari, conforme a imagem (Fig.1). Os impactos ambientais e sociais são praticamente congênitos ao início da efetivação destes projetos, entretanto, o agravamento da questão ambiental no município teve início com as mortandades de peixe em agosto de 2014.

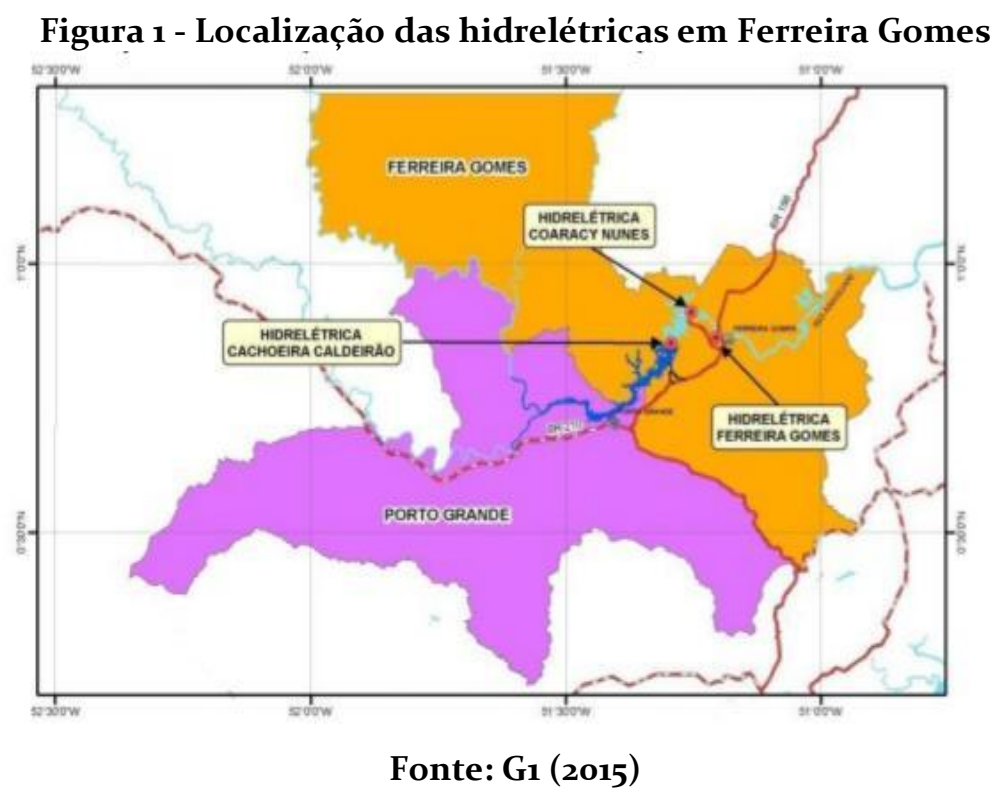

De 2014 a 2019 a mortandade continua constante, os moradores locais, em sua maioria pescadores, são intensamente prejudicados pela morte dos peixes que afeta diretamente a economia do município banhado pelas águas do Rio Araguari, portanto, a própria subsistência da população é afetada: "Eu cheguei a vender 6o quilos de peixe por mês. Atualmente eu não faço isso e não tiro o sustento da minha família do rio“, 
disse a pescadora Valdirene Ramos, em Ferreira Gomes $(G 1,2015 a)^{2}$. O relato desta pescadora sintetiza a dimensão dos impactos ambientais no município, privando famílias tradicionais de seu principal meio de subsistência. "Está complicado, porque não conseguimos pescar nem para comer" $(\mathrm{G} 1,2015 \mathrm{a})$ relata outra pescadora. "Até a caça não tem mais porque com a hidrelétrica os bichos foram embora” relata um caçador (G1, 2015a). O professor Carlos Afonso Ferreira, de 35 anos, relembrando o susto com a quantidade de peixes mortos no Rio Araguari em 2014, disse: "a quantidade de peixes era muito grande. Eles ocuparam uma área de cerca de dois metros longe da água após a maré ter secado. Isso sem contar o que pode ter ocorrido ao longo do rio nas comunidades ribeirinhas", disse. (G1 2014)³.

No período dos primeiros ocorridos em 2014, a suspeita levantada pelos pescadores e a comunidade em geral consistiu na hipótese de que a mortandade de peixe foi consequência de "uma poluição das águas" pelas hidrelétricas, o que gerou um contexto generalizado de medo de ingerir o pescado supostamente poluído, acarretando intensos conflitos no pequeno município de Ferreira Gomes estruturado economicamente pela pesca. Conforme o relato da presidente da Associação dos Pescadores de Ferreira Gomes, Benedita Tavares: "Não temos peixes para oferecer para a comunidade por causa do medo de consumir um alimento poluído" (G1, 2014).

Destarte, um dos primeiros danos psicossociais a atingir a população tratou-se do impacto na sua alimentação típica, na qual o pescado, a caça e frutos coletados preenchiam outrora com fartura as mesas das famílias ferreirenses. A caça de animais para subsistência, na região de Ferreira Gomes, é central enquanto proteína alternativa ao pescado, que é o principal alimento das populações amazônicas em geral, portanto, a falta desses animais é o fator crucial a gerar o déficit nutricional pelo qual passou a comunidade ferreirense no supramencionado período.

Em 2014, o Instituto de Meio Ambiente do Amapá (Imap) concluiu que não foram encontrados indícios de poluição no Rio Araguari, entretanto, em 2018, estudos

2 Disponível em: http://g1.globo.com/ap/amapa/noticia/2015/11/peixes-sao-achados-mortospela-4-vez-no-rio-araguari-em-ferreira-gomes.html. Acesso em: 11/o8/2019

3 Disponível em: http://g1.globo.com/ap/amapa/noticia/2014/o9/laudo-descarta-poluicao-emrio-onde-peixes-mortos-foram-encontrados.html Acesso: 11/o8/2019 
técnicos do Instituto de Meio Ambiente e Ordenamento Territorial e da ProcuradoriaGeral da República (PGR) comprovou a responsabilidade da Hidrelétrica Cachoeira Caldeirão por uma supersaturação da água, o que resultou na mortandade do pescado $(\mathrm{G} 1,2019)^{4}$. Somente em um período de um ano, entre 2016 e 2017, registrou-se a morte de três toneladas de peixes no Rio Araguari. Em 2018, após quatro anos do primeiro ocorrido, por pressão da população e movimentos sociais, a Justiça Federal determinou o bloqueio de R\$ 2 milhões da Hidrelétrica Cachoeira Caldeirão, no entanto, sem nenhuma condenação $(\mathrm{G} 1,2019)$. (ver fig.2 e 3)

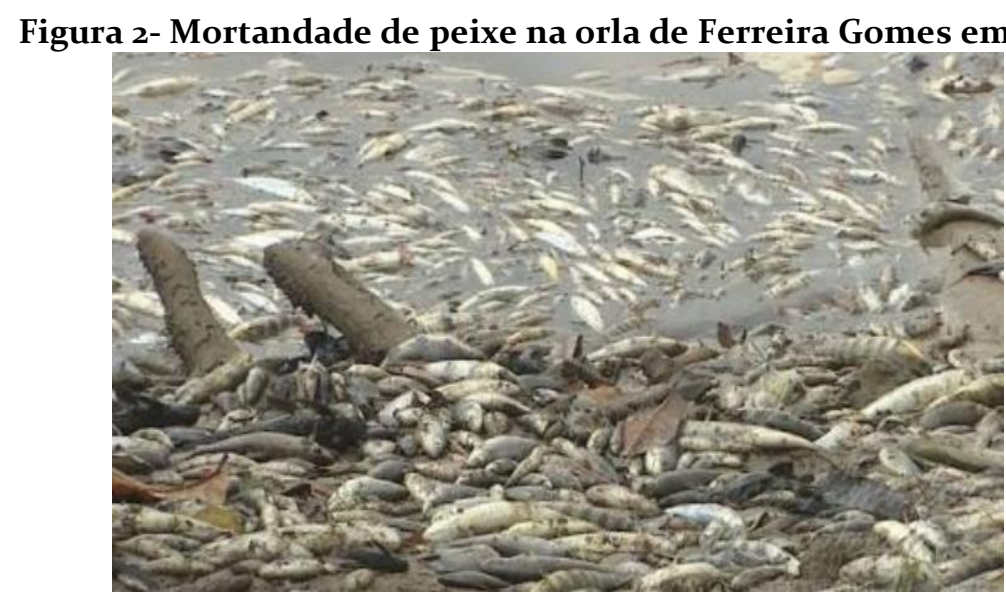

Fonte: G1 (2016)

"A mortandade acontece em pleno período de reprodução dos peixes, o pescador não pode pescar para vender" (G1, 2019) denuncia Morone Guimarães presidente regional do Movimento dos Atingidos por Barragens (MAB). Com a implantação das UHE, o principal modelo de subsistência e produção de renda estruturado na pesca, caça e colheita de produtos agrícolas foi estruturalmente afetado pelas modificações fisiográficas e ecológicas na região (CABRAL, 2019; PANTOJA, 2012;), o que também dimensiona modificações simbólicas nas relações pressupostas na territorialidade da comunidade. Neste interim, no âmbito da subsistência e do "alimentar-se" os afetos e sentidos empíricos possuem papel fundamental, neste

4 Disponível em: https:/g1.globo.com/ap/amapa/noticia/2019/o4/o4/pescadores-resgatampeixes-de-area-de-reproducao-esvaziada-por-acao-de-hidreletrica-no-ap-video.ghtml Acesso em: $11 / 08 / 2019$ 
contexto constatou-se, através da observação participante, a presença de conteúdos representacionais ancorados à dimensão socioafetiva, isto é, aquela em que o ator social possui proximidade relacional com seu meio e mantendo sentimentos de afeto em relação ao lugar onde mora, a profunda ligação com a terra e as relações comunitárias (RODRIGUES, 2012, p.41) tal como ilustrado por uma moradora do bairro matadouro:

\begin{abstract}
Nós não podemos pescar porque os homens da lei não deixam porque tá na piracema [período de reprodução] né? Mas essa bichona aí [referindo-se a hidrelétrica] pode matar nossos peixes a vontade, pescador não tem um peixe para matar a fome nem para vender, é injusto! [...] Minha terrinha aqui já foi boa, nós todos acreditamos que a empresa [referindo-se a hidrelétrica] ia trazer trabalho e melhorar nossa condição né? Agora nós sofremos em ver nosso rio cheio de peixe morto, nossa terrinha sofrendo [...] (Trabalho de Campo).
\end{abstract}

Conforme os discursos dos moradores de Ferreira Gomes, torna-se possível interpretar que um dos elos da cadeia de conexões entre sociedade e ambiente tende a ser o território (RODRIGUES, 2012, p.38). Raffestin (1993, p.143) proporá que o espaço é um substrato preexistente ao território, portanto, "ao se apropriar de um espaço, concreta ou abstratamente, o ator 'territorializa' o espaço” (RAFFESTIN, 1993, p.145), neste sentido o território surge marcado por relações funcionais e simbólicas, passíveis a influenciarem questões sociais e psíquicas dos indivíduos (SOJA, 1993, p.148). Não obstante, a territorialidade marca o desenvolvimento de um pertencimento afetivo em relação a dado lugar, trata-se de uma característica intrínseca das comunidades, concretizando-se mediante a convivência cotidiana e relações afetivas com a região (HAESBAERT, 1994, p.212). Sobre suas impressões acerca das mortandades de peixe e sua ligação com a terra, relata o pescador conhecido como seu Zé:

Rapaz o que estão fazendo com nosso rio é uma pilantragem! Antes era cheio de matrinxã, pacu, tucunaré [Nomes de peixes populares na região] e agora nós não temos quase nada, vira e volta pegamos um acará e umas piraninhas [Nomes de peixes] mas não enche o bucho nem dos meus netos pequenos [...] se meu pai estivesse vivo seria uma tristeza só... minha família pesca nesse rio faz muito tempo, meu avô pescava aí conhecia tudo desse rio aí e dessa terra nossa aqui mas ai quando vê chega os homens né? E constroem esse negócio gigante aí vão embora e deixam prejuízo para nós, como que é um negócio desse? (Trabalho de campo) 
Portanto, a própria formação de um território dá às pessoas que nele habitam a consciência de sua participação, provocando o sentido da territorialidade que, de forma subjetiva, cria uma consciência de confraternização entre elas na dimensão das práticas e usos coletivos deste mesmo território (RODRIGUES, 2012, p.38), assim como se pode entrever no relato de seu Zé, sua família mantém a tradição, agora ameaçada, de pescar no rio Araguari há gerações, desde seu avô até seu filho mais novo, o que exorta os impactos simbólicos destes megaprojetos na constituição cultural de um povo ao destituir tradições e costumes.

Todavia, o grande impacto nas relações de territorialidade da comunidade ocorreu em 2015, quando houve um aumento repentino do nível do Rio Araguari, o que causou uma enchente histórica atingindo 445 casas em 7 de maio de 2015 (G1, 2015b)5 obrigando pelo menos 300 famílias a deixar suas residências e irem para abrigos, comércios e prédios públicos que também foram invadidos pela água. Não obstante os incomensuráveis danos materiais, psicológicos e socioambientais deste desastre à população, somente três anos depois, em 2018, a Justiça Estadual aceitou o laudo que aponta a culpa da hidrelétrica Cachoeira Caldeirão no aumento repentino do nível do Rio Araguari (G1, 2019). De acordo com os peritos, o rompimento numa estrutura de contenção de água da hidrelétrica e falta de aviso prévio provocou a enchente:

[...] houve rompimento da ensecadeira da UHE Cachoeira Caldeirão por erosão interna (piping), e não abertura controlada, como sustentou a UHE; [...] o rompimento ocorreu a partir das 7 h da manhã, e somente às $1_{50}$ foi feito pela UHE o primeiro comunicado acerca do incidente; não houve consulta aos gestores dos outros empreendimentos, nem aviso aos órgãos públicos e à população $(\mathrm{G} 1,2015 \mathrm{~b})$.

Até o presente momento da escrita deste artigo (Agosto de 2019) não houve condenação da empresa tampouco o levantamento dos danos causados pelo ocorrido.

5 Disponível em: http:/g1.globo.com/ap/amapa/noticia/2015/o5/rio-sobe-e-invade-ruas-emferreira-gomes-populacao-culpa-hidreletrica.html Acesso em: 11/o8/2019 
Figura 3 - Enchente artificial do rio Araguri provoca inúmeros danos à população local

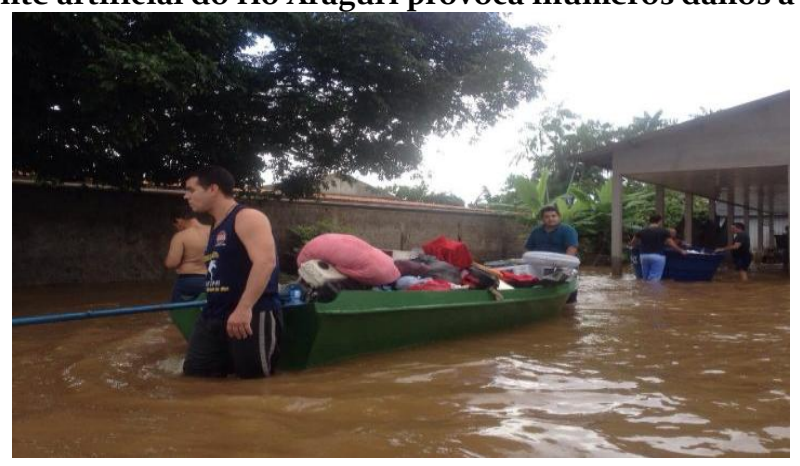

Fonte: G1 (2015)

\section{Mobilização social e resistência da população de Ferreira Gomes}

Neste contexto caótico, o movimento dos atingidos por barragens (MAB) é um dos principais meios de organização política e mobilização social da população de Ferreira Gomes perante os variados descasos do poder público e dos constantes ataques a direitos humanos fundamentais. Neste ínterim, entrevistamos moradores e pescadores da região que atuam neste movimento, incluindo uma entrevista com Morone Guimarães, o líder regional do movimento supracitado. Destarte, chamo a atenção para a importância das vozes destes atores sociais neste contexto conflitivo, enquanto "nascidos e criados" em Ferreira Gomes e prejudicados pelas hidrelétricas, seus relatos representam e dimensionam a resistência e a resiliência das comunidades tradicionais em face da lógica capitalista devoradora, explicitando os meios de resistência empregados por estes ativistas em defesa da Amazônia. Pode-se entrever nas colocações dos diversos pescadores e moradores locais, uma síntese, do ponto de vista nativo da região, do processo de instalação e efetivação destes projetos econômicos.

Ao tratar das etapas iniciais que antecedem a efetivação da hidrelétrica, no momento da viabilização do local para a construção usina, Morone Guimarães narra à forma do relacionamento da transnacional responsável pela UHE, através de seus agentes, com a população local:

Eu sou atingido pela barragem também, meu terreno ficava passando a ponte, e o cara [referindo-se ao representante da empresa administrativa da UHE] chega 'olha, queremos que tu saia daqui, queremos comprar teu terreno'. Eu 
disse 'meu terreno não tá a venda, comprei meu terreno com o intuito de me aposentar, fazer minha casinha e viver tranquilamente, $1 \mathrm{~km}$ de asfalto na frente e o rio Araguari atrás, reservado com toda a natureza aqui'. Aí eles chegaram 'não, você tem que sair daqui, nós vamos construir uma hidrelétrica aqui' (Trabalho de Campo).

Esta narrativa ilustra de forma sintética o embate entre lógica capitalista versus lógica do bem-viver das comunidades locais, o próprio caráter de necessidade no discurso do representante da transnacional "você tem que sair daqui" ilustra a compulsão do modus operandi capitalista que passa por cima indiscriminadamente com seu "rolo compressor", para usarmos a alegoria de Marx em O Capital (MARX, 2013, p.133).

Demonstrando toda a coerção das empresas para com a população local e, principalmente, a subordinação do poder público das instituições governamentais ao poder econômico capitalista, Morone retrata:

Não temos nenhum canal aberto com a empresa, eles não reconhecem, não reconhecem. Quando nós queremos algo, nós temos que ir pra frente, se organizar e ir pra luta, para o protesto, para conseguirmos alguma coisa porque pelos órgãos competentes que deveríamos ter como IMAP, Ministério Público é difícil... é difícil. Até o próprio Estadual... Temos esse receio. (Trabalho de Campo)

Neste relato, pode-se entrever a contradição na qual o desenvolvimento econômico-industrial muitas vezes se consolida em detrimento dos direitos das comunidades locais, a falta amparo legal e jurídico do Estado em relação às reinvindicações de Morone explicita a supracitada contradição.

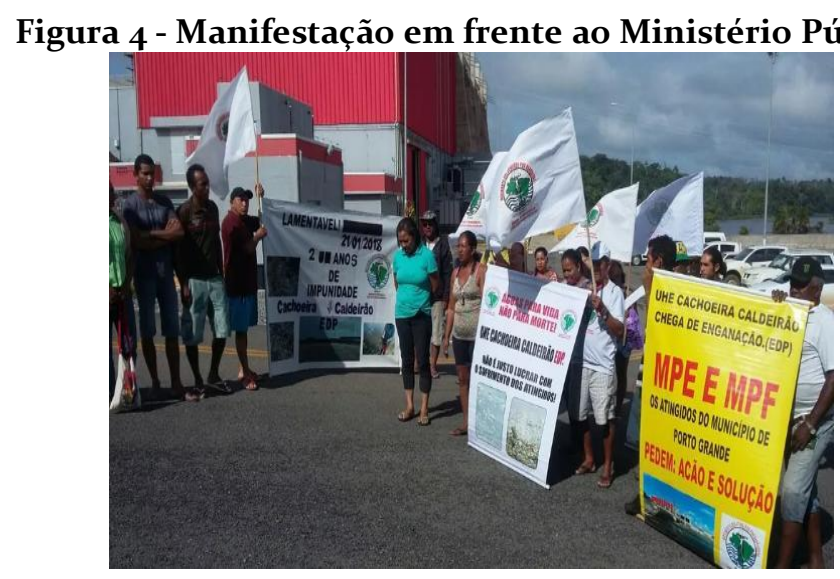

Fonte: G1 (2015a) 
Um relato importante dentre as entrevistas realizadas está o registro da fala de Raimundo Souza, ativista no MAB e pescador, no momento em que perguntamos acerca dos impactos da mortandade de peixe, Raimundo relata:

\begin{abstract}
Não é só pescador que depende do peixe... Então era tradição aqui em Ferreira Gomes final da tarde agora, cinco horas da tarde, a comunidade ir pescar, pegar seu peixe para poder se alimentar e hoje não tem isso, você não consegue mais pegar peixe aí [...] a hidrelétrica mudou nosso rio, nossa terra, nos nossos locais de pesca não tem nem acarazinho [Peixe de pequeno porte]. Então hoje com a mortandade de peixe e trabalho que não tem, tem um monte de pessoas passando necessidade, fome mesmo... Fome, vocês vão ver muitas pessoas passando necessidade que não tem por onde se alimentar (Trabalho de Campo).
\end{abstract}

O relato do pescador Raimundo aponta para uma das consequências inerentes ao processo de instauração dos grandes projetos na Amazônia: a desterritorialização de comunidades tradicionais. Enquanto um complexo processo de ressignificação de atitudes, crenças, tradições, práticas habituais, dimensionando desordem e fragmentação da territorialidade, a desterritorialização implica um impacto brutal às comunidades, pois ocorre quando o domínio territorial é perdido e aquilo que antes era concreto desmancha-se no ar, cedendo lugar ao sentimento de perda afetiva e desvinculação com a terra (RODRIGUES, 2012, p.44). Esta fragmentação se concretiza gerando enfraquecimento nas relações intra e intergrupais, afetando individualmente os atores desterritorializados (HAESBAERT, 1994, p.210).

Doravante, Raimundo explicita sua indignação:

Então tivemos pescadores que morreram afogados em frente a hidrelétrica aí... Porque eles iam pescar escondido pra lá, já que não tem aqui, pescar escondido a noite e quando abriu as comportas lá, alagou o barco e um sobreviveu e o outro morreu aqui em frente o rio Araguari... A água é pra vida e não pra morte, né? Então, tá aí o rio, nosso, rio da comunidade e essas empresas aí gerando riqueza com o nosso rio, mandando pra fora e pra comunidade não fica o que deveria ficar, as compensações que deveriam ficar (Trabalho de Campo).

Resistir para as populações desterritorializadas, conforme Rodrigues (2012, p.38), é um ato inerente à dimensão social que intermedia os processos de negação e 
aceitação da nova realidade instaurada, em que os atingidos vivenciam recentes mudanças, sem, entretanto, perder a profunda conexão com as raízes, eles incorporam as consequências dos impactos à sua cultura, gerando modificações estruturantes e funcionais em relação a configuração da vida social anterior (OLIVEIRA, 2000, p.110), o que implica que a destituição de hábitos, tradições e valores perpassa pela resistência à imposição de novos comportamentos e se encerra na superação em relação à situação fragmentária inicial e à reformulação de valores ora destituídos (LEFEBVRE, 1991, p.18). Em síntese, todos esses relatos dimensionam o próprio paradoxo imposto pela colonialidade do saber e do poder do sistema-mundo capitalista à região e seus habitantes: a Amazônia erigida em destaque no debate mundial por sua dimensão verde e ecológica, sobretudo sua importância para o equilíbrio climático global, se vê hoje como uma região que passa a contribuir fortemente para o agravamento da situação ambiental global através da devastação de sua fauna, flora e de seus povos pela hegemonia de interesses econômicos (GONÇALVES, 2018, p.63). A máquina industrial impulsionada pela lógica produtivista e irresistível da acumulação de capital difunde destruição por onde se instala: a morte da floresta, dos rios, dos povos são um meio para o lucro de poucos. Deste modo, o perverso dessa contradição é o avanço acelerado da perda de diversidade biológica e cultural e a violência contra os povos com a expulsão das populações e os assassinatos, tornando explicito a incapacidade do Estado em garantir o direito a vida e ao bem-viver destas pessoas (GONÇALVES, 2018, p.77). Todavia, o que se diagnostica é a própria instrumentalização do aparato estatal em prol de interesses obscuros e exógenos ao interesse público, constata-se a proeminência de interesses sobre a Amazônia em detrimento de interesses da Amazônia, das comunidades tradicionais que nela habitam. Destarte, o modelo de desenvolvimento vigente na região amazônica não poderia ser classificado senão como modelo necro-econômico: a destruição e morte enquanto condição para sua instauração.

\section{Em vias de conclusão}


Conforme os dados empíricos apresentados acima constata-se: primeiramente, a subordinação dos aparatos estatais (Prefeitura, Governo Estadual, Ministério Público) aos interesses das transnacionais que administram as usinas hidrelétricas; a negligência do Estado para com a população de Ferreira Gomes, deixando-a desprotegida institucionalmente perante os vastos impactos e infrações de seus direitos; do ponto de vista energético, o alicerce da justificação dada para legitimar as construções das usinas hidrelétricas, a saber, a geração de energia e desenvolvimento para a região, é contrariada pelos dados empíricos: a disparidade socioeconômica da Amazônia em relação às outras regiões no Brasil, enfatizando o contraste inter-regional, resulta no grave número de 46,6\% da população do estado do Amazonas (NOBRE, 2016, p.14), por exemplo, que não possui acesso à rede de energia elétrica em suas residências, neste sentido, apesar de ser a maior bacia hidrográfica do mundo e consequentemente possuir grande potencial hidrelétrico, a região amazônica condena seus habitantes a estratégias alternativas de acesso à energia, destarte, o falso discurso do desenvolvimento e universalização do acesso a energia elétrica dissolve-se perante o contraste com a realidade regional.

Na esfera dos impactos avaliados, principalmente no que tange a dimensão da territorialidade, desvela-se que a própria estruturação espacial das usinas hidrelétricas pressupõe a desestruturação e, doravante, reestruturação dos espaços impactados, em decorrência das desapropriações necessárias para a efetivação destes grandes projetos, implicando a apropriação do espaço vivido, percebido e simbólico/afetivo dos moradores. Conforme Rodrigues (2012, p.50), a reterritorialização, a partir da reconfiguração do modus vivendi de comunidades devido aos impactos nas áreas afetadas pelas usinas, vem cimentar a criação de novos vínculos em substituição aos perdidos, transformando significações e atualizando os vínculos emocionais, destarte, o território é ocupado não apenas de maneira física, mas a própria ocupação pressupõe conteúdos coletivos, relacionados a processos históricos entre as pessoas. De modo que a territorialidade pode ser compreendida não somente pela perspectiva do domínio ocupacional, mas como uma apropriação que incorpora as dimensões simbólica, identitária e afetiva (RODRIGUES, 2012; RAFFESTIN, 1993; HAESBAERT, 1994). 
Portanto, a partir de um olhar sociológico sobre os impactos ambientais e sociais decorrentes dos grandes projetos para a Amazônia, especificamente no caso de Ferreira Gomes, comparando as fundamentações e os dispositivos discursivos legitimadores do desenvolvimento com a realidade empírica amazônica, constata-se um esvaziamento do conceito de desenvolvimento e progresso: não se pode falar em desenvolvimento quando não ocorre uma correspondente participação da sociedade nos benefícios materiais e imateriais gerados pelo crescimento econômico, quando o modelo vigente produz mais danos do que benefícios, quando o lucro é mais importante que os direitos fundamentais das populações tradicionais (LOUREIRO, 2012, p.529). Neste sentido, torna-se premente buscar alternativas de desenvolvimento para a Amazônia que sejam norteadas por paradigmas mais solidários e distributivos e que tenham suas bases fincadas em formas próprias e mesmo inovadoras de organização da produção, que sejam socialmente mais integradoras e mais harmonizadas com a natureza.

\section{Referências}

Almeida, Carolina S. 2016. Conflitos na Exploração de Recursos Naturais em Terras Indígenas: Um Estudo de Caso nas Américas. Revista Política Hoje, Pernambuco, V.23, p. 93-111.

BHABHA, Homi apud FRIEDMANN, Susan Stanford. 2001. O falar da fronteira, o hibridismo e a performatividade: teoria da cultura e da identidade nos espaços intersticiais da diferença. Rev. Crítica de Ciências Sociais, V. 61, p. 1-28.

BOURIDEU, Pierre. O Poder Simbólico. Rio de Janeiro: Bertrand Brasil, 2006.

CABRAL, J. Batista. 2019. Dinâmica da paisagem na bacia hidrográfica da Usina Hidrelétrica de Ferreira Gomes -Amapá, Brasil. Caderno de Geografia, v.29, p.12-33.

GOMES, Romeu. A análise de dados em pesquisa qualitativa. In MINAYO, Maria Cecília de Souza. Pesquisa Social: teoria, método e criatividade. Petrópolis: Vozes, 1994 .

G1-Portal de Notícias. Pescadores resgatam peixes de área de produção esvaziada por ação de hidrelétrica. Disponível em: 
https://g1.globo.com/ap/amapa/noticia/2019/o4/o4/pescadores-resgatam-peixes-dearea-de-reproducao-esvaziada-por-acao-de-hidreletrica-no-ap-video.ghtml

G1-Portal de Notícias. Peixes são achados mortos pela $4^{\circ}$ vez no rio Araguari em Ferreira Gomes. Disponível em: http://g1.globo.com/ap/amapa/noticia/2015/11/peixes-sao-achados-mortos-pela-4-vezno-rio-araguari-em-ferreira-gomes.html

G1-'Portal de Notícias. Laudo descarta poluição em rio onde peixes mortos foram encontrados. Disponível em: http://gi.globo.com/ap/amapa/noticia/2014/og/laudodescarta-poluicao-em-rio-onde-peixes-mortos-foram-encontrados.html

G1-Portal de Notícias. Rio sobre e invade ruas em Ferreira Gomes. Disponível em: http://gi.globo.com/ap/amapa/noticia/2015/05/rio-sobe-e-invade-ruas-em-ferreiragomes-populacao-culpa-hidreletrica.html

HAESBAERT, Rogério. O mito da desterritorialização e as "regiões-rede". 1994. Anais do V Congresso Brasileiro de Geografia. Curitiba: AGB, v. 1, p.206-14.

IBGE - INSTITUTO BRASILEIRO DE GEOGRAFIA E ESTATÍSTICA, 2016. Resultado dos Dados Preliminares do Censo - 2010. www.ibge.gov.br/cidade

LOUREIRO, Violeta Refkalefsky. 2012. A Amazônia no século 21: Novas formas de desenvolvimento. Revista Direito GV, São Paulo, V. 8, p. 527-552.

LEFEBVRE, Henri. O direito à cidade. São Paulo: Moraes, 1991.

MARX, Karl. O Capital: Crítica da economia política. Livro I: O processo de produção do capital. São Paulo: Boitempo, 2013, p. 113-158.

NOBRE, Fábio Rodrigo Ferreira. 2016. Recursos Naturais na Região Amazônica Cooperação ou Conflito. Revista Política Hoje, Pernambuco, V. 23, p. 65-91.

OLIVEIRA, José Aldemir. Cidades na selva. Manaus: Valer, 2000.

PORTO-GONÇALVES, Carlos Walter. Amazônia: encruzilhada civilizatória. Tensões territoriais em curso. Obrajes: IPDRS - Instituto para el Desarrollo Rural de Sudamérica, 2018, p. 25-47.

PANTOJA, M. Thalez. 2012. Impactos socioambientais decorrentes dos projetos hidrelétricos na bacia do Rio Araguari: do aumento populacional a disseminação da malária. PRACS -Macapá, v. 4, p. 61-74.

RODRIGUES, A. Impactos sociais da desterritorialização na Amazônia brasileira: o caso da hidrelétrica de Balbina. 2012. Emancipação, Ponta Grossa, V.12, p. 35-53. 
RAFFESTIN, Claude. Por uma geografia do poder. São Paulo: Ática, 1993.

SOUZA, Márcio. Amazônia e Modernidade. 2002. Estudos Avançados, V.16, p. 31-36.

SOJA, Edward. Geografias pós-modernas: a reafirmação do espaço na teoria social critica. Rio de Janeiro: J. Zahar, 1993. 